\title{
THE MICROSCOPE AND LTEE.
}

BX EDWALD F. BIGELOW.

Stamford, Conn.

"What is life?"

The simplest, most universal and stupendous phenomena are those of the distinctions between living and lifeless things. The more careful the observations, the greater the wonder. Bring to bear upon the subject all the accumulated knowledge and all the skill of the greatest intellects, and the answer to the question, "What is life?" still tarries. It is the ever fleeing will o' the wisp that leads the followers through fields and byways more and more enchanting. Greatest values lie not in the goal, which may never be reached, but in the race itself.

Even to the most unobservant, at least, one of the threefold divisions of this great question must appeal with deep and peculiar significance-what it is, what its origin and whither its tendeney.

In the investigation of this greatest of mysteries, the most efficicnt aid is the microseope. By it we enter the hidden, fascinating and mysterious realm where the processes of life go on beyond the power of the unaided cyc to detect.

This instrument, whose performance seems almost to be in the field of magic, has cnabled us to reach the wonderfully little on earth, as the telescope has helped us to explore the stupendously great of the heavens above.

Beneficial, indecd, is the microscope in the arts, in commercein the examination of fabrics, and the detection of adulteration. It is of great utility in the study of rock structure and the identifcation and study of minerals. Profitable and pleasant is it likewise in observing the formation of crystals, and it has rendered much service in the advancement of chemistry. But vastly more than alj these is its utility in investigating the processes of Iife.

In the life of every human being, fundamental questions are the first to appeal to growing intelligence. "What is this?" "What is it for?" All young children are true observers-natural scientists. As age advances, the greater part of mankind chooses or is forced, in the struggle for existence, to ignore these great questions. 
and to give chief attention to the affairs of so-called everyday lifebusinesa, society, politics, art or diversion. The great problems are set aside as if they never existed or have been all fully solved.

But to the comparatively few, the question "What is life?" never loses its interest, nor the wonderful microscope its efficiency. It is to these that biological microscopy holds fascination as one of the grandest sciences-one of the highest occupations of the human mind.

Biology demands close, carcful, accurate obscrvation. Objects intended only for examination by the rnaided vision demand as much care as do those prepared for the use of the lighest powers of the microscope. But observation is not all. Those who have unlocked some of the mysteries of nature have, in many instances, been aided by scientific imagination, by the creation of a hypothesis, to be worked up to and demonstrated if well founded, or discarded if incorrcct. The abandoning of fallacious hypothesis has been difficult for some biologists, who have cherished their theorics as a parent would cherish a crippled child, clinging to them fondly, although no fact can be so twisted or distorted as to fit into the grooves prepared by an overzealous fancy.

Fundamental and primitive among the working hypotheses of biological mieroscopy is the nature of the energy that we call life. Till demonstrated, if such a remote and much desired ultimatum were possible, all investigations must be arraigned for or against the correlation or equivalence of life with the forms of energy discussed by the physicist.

What are its relations to light, heat, electricity and chemical forces? Is the phenomenon of life due to any or to all of these, or is it the effect of some unknown and undiscoverable agency? The present state of science, while not issuing a positive cdict, does at least favor with some probability of correctness the hypothesis of a force different from any at present known in the domain of chemistry or of physies.

The living matter in the cell was originally called protoplasm, but in 18\%2 Professor Beale introduced the word bioplasm and applied it exclusively to living protoplasm. By some scientists the terms protoplasm and bioplasm are used interchangeably, but 
the original intent of the term bioplasm, if closely adhered to, makes a convenient distinction.

According to this view, protoplasm is always protoplasm, "the physical basis of life," dead or alive-even if cooked. With death, bioplasm ceases to be formative matter, and becomes so much ordinary dead protoplasm or formed matter.

Bioplasm is, therefore, living, growing, active protoplasm; living, growing protoplasm is bioplasm. Dead bioplasm is only dead protoplasm, and dead protoplasm is dead bioplasm. At present, however, this term bioplasm is but little used by scientists. Protoplasm applies to both the living and dead basis of life.

Animal or vegetable matter that has accomplished its growth, when it no more increases by division or by addition of new matter, when it simply lives unchanged is formed of protoplasm, but is not correctly bioplasm, for bioplasm must manifest activity in the form of increase and reproduction.

Protoplasm may be alive and quiescent; there can be no such thing as entirely quiescent bioplasm. When bioplasm becomes quiescent, it has ceased from formative work and become formed material. It lives, but as a quiet protoplasmic structure, complete morphologically and about ready to die and disappear, to give place to some active protoplasm which then becomes bioplasm.

In this animal and vegetable bioplasm, which may be obtained in many ways, are to be observed the phenomena of life. Magnifying. power, only sufficiently high to do this work, to show structure and action is the best. It is probable that no means will ever be devised whereby a knowledge of structure will result in a knowledge of the cause of action. How this transparent bioplasm docs its work is information that could probably not be obtained if the ability of microscope objectives could be increased even beyond the theoretical limit of resolving power of 146,543 lines to the inch in white light, or of 158,845 in monochromatic blue light.

To make a chemical analysis of living matter is at present impossible. Biologic investigations must then be chiefly by microscopical methods. The question naturally arises: Why pursue a science that offers not even a probability of an uitimate reward? The What is the Infinite, and is not to be comprehended by the 
finite. Demonstration can be made of what life is not, and observations of what it does may be made with much profit.

The nucleus is the point at which the life of the cell centers; there is no known living cell without a nucleus. This has been proved by the observations of scientists, who cut an infusorian into several parts, and each lived, grew, and reproduced itself, provided even a small portion of the nueleus was retained in the part, but died if no portion of that complex structure remained. Thus the life of the cell is now known to be centered in the nucleus.

We know imperfectly and incompletely the structure of the living, and the chemical composition of the dead nucleus, but the life itself eludes us.

Reproduction and growth always begin in the nucleus; reproductive formation always begins with the union of two living cells. This is seen, almost at will, in certain infusoria. Two of these minute aquatic animals meet, apparently by chance; at once the two bodies become united, the protoplasm (bioplasm) of the one mingles with that of the other, and the nuclear changes take place and new individuals are formed.

In the nucleus is the potential throne of life, where life abides, makes its laws, and whence it issues its commands. Whatever the life of this cell may be, it is primarily in the nucleus.

Biological microscopy, therefore, chiefly concerns itself with the study of the cell and its nucleus, asking these questions:

1. What is life?

2. What are its relations?

3. What does it do?

"What is life?" then becomes the great question to be considered in threefold relations-essence, associations, and activity.

A comprehension of life itself is not within the power of life. It will doubtless remain "the great mystery" before which there stands a Great Unknowable that says, "so far shalt thou go and no farther." Of this great Infinity, science knows and can know nothing except to name it p-0-w-e-r, or l-a-w. It has been made known only through revealed religion and is called God; and even then only sufficient made known for needs rather than to gratify curiosity, with promise of knowledge in its fullness, when the val- 
ley of this life shall be vicwed from the summits of the mountains of the eternal and real life.

In its associations, the manifestations of life closely ally it with the powers of chemistry and physics, but at the same time distinctly separate it from both. The physical basis of life, protoplasm or bioplasm, can be analyzed. But the reverse process is impossible. The constituent chemical elements can never be recombined nor the physical pbenomena so stimulated as to produce life. Destructions may be from various cartses, but production only from natural sources and from previous life. Since matter and life were created, the first, so far as we know, can neither be produced nor destroyed, and the latter can not be created.

"Omne vivum ex vivo" is the unchangeable biologic edict. Scientific evidence is more and more convincing and conclusive regarding the direct operation of vital powcr. The difference between life and death and the difference between all kinds of growth in the living and all kinds of aggregation in the non-living are, always were, and forever will be absolutely different and irreconcilable.

Life is not the outcome of mechanical and chemical forces, though it may utilize both for its, welfare.

Some physicists and chemists, using improved instruments and methods of research, investigating with marvelous delicacy and approaching nearer absolute knowledge, have naturally looked forward to the discovery of something basic in the living thing that can be taken apart and put together; chemists have been deluded by this theory of synthetic life.

The mieroscope in biology destroys this hypothesis by demonstrating that the primal cell is not merely a compound but a structure, not a syntheses of masses, but a machine.

A machine implies more than a combination. There is back of it a formative, designing mind. Mixture is not enough.

No substance has yet been nor can be discovered in the laboratory that will live, move and grow like every particle of matter that has lived, moved and died. The gulf betwecn the living and nonliving grows wider and wider with the advance of biological microscopy. There is no reason for thinking it ever can be bridged or filled up. The microscope has not yet disclosed any intermediate 
stage, no half life or half death in case of a definite cell of bioplasm. One may be more active than another, or at other times, but it is in all cases either life or death.

Biological microscopy demonstrates that all living matter has a position of its own, difference in origin, multiplication, growth and action, and influence of environments that are distinct, in. fact, superior to physical and chemical laws, often overcoming them when in opposition. The laws of matter are not the laws of life. Tife is distinct from chemical and physical laws, though associated with them.

The third division of biological microscopy, a consideration of the activities of life, is the most prolific in definite and satisfactory results. A drop of water from an aquarium or a pool reveals on microscopical examination a world of things, not unlike the scenes on a street.

Many things, some living, some not. A simple particle of life, the amoba is well worth careful consideration. 'Though but a speck of matter, it is still living and shows life in many of its manifestations and activities. A portion of the protoplasmic body extonds and the rest is drawn to it. It approaches a bit of material and leaves it or surrounds and assimilates it as food. From the food material engulfed, the nutrient portions are transformed into its own living substance. In the rery beginning of its life there are the phenomena of locomotion, choice, nutrition, and reproduction. One little mass of jiving matter has performed all the functions of life.

Perhaps the larger and more complex forms, not even excepting man, are but aggregations of cells in which duties are even simpler than in amceba. Instead of all the duties of life being performed by one ccll, there are cells spccially assigned for various functions; some digest, some feel, some reprodnce the species, and others are differentiated for various specified duties. The study of these specialized cells demands the use of the microscope and yields satisfactory results.

Among the activities of life as revealed by the instrument, none are more interesting or wonderful than the self-sacrifice of the leucocytes or white corpuscles of the blood. They take up 
minute impurities, carry their load out and free the body, but they themselves perish. No patriot, in dying for his country, ever exhibited more self-sacrifice than these little corpuscles, the guards of the body.

The study of activities involves the study of structure. Modern research, with. improved lenses, shows that a cell is not, as its name implies, a vessel empty or filled with fluid, but is itself a highly organized, differentiated structure. Its contents are not a homogeneous mass, but in intricacy of structure and diversity of duty nearly, if not quite, rival that of the whole structure. The nucleus, the astrospheres, the centrosome and the network of chromatin have each an individual and distinct function to perform. As with the various cells of the whole structure, so in each part of the cell there is a willing assumption of individual responsibility.

These are but the gates, fascinating though they be, to the great fields of biological microscopy. Upward through the serics, from low to high, in parallel lines of zoölogy and botany, the investigation may continue.

To diversities without confusion, to beauties of great attractions, to wonders that instruct as well as amaze, to mysteries that baflle but never discourage, are the invitations of biological microscopy.

Structure, functions and activities have their great reward, but the microscopist who has witnessed growth has been near to a natural phenomena, even more awe inspiring than death. It is not in death but in life that the ground is holy. Witness the growth of a slender filament from a pollen grain, or the extension of a thread of fungus, and the microscopist achieves a result worth many hours of patient toil and study. It brings the observer closer to the Great Infinite that we know is near us at all times, but from which our present limitations exclude us from full communion. Only a glimpse into the Great Unknowable. Not forcver shall the veil intervene. "For now we see through a glass darkly; but then face to face."

The microscopist, in researches in biology, can go forward with enthusiasm and hope, that although research will never answer 
the great question, yet is he confident that as each generation adds a little certain knowledge to the world, there may come in time an accumulation of facts regarding living substances, so complete that while the great mystery voiced in that greatest of scientific questions, "What is life?" may not be answered except in its activities and phenomena, there may cease to be the supreme question in its essence.

Through cell structure, simple individualism, greater differentiation, even to bighest complexities, biological miscroscopy leads its devotee. And at each advancing step towards the Great Mystery our appreciation of Luther's statement, "To have studied well is to have prayed well," should increase.

\section{AN EXPERIMENT IN RESONANCF.}

BY E. C. WOODRUFF,

Instructor in Physics, Lake Iticw High School, Chicago.

Without doubt the most important things in elementary acoustics are these: (1) Simple Harmonic Motion. (2) The relation between frequency, wave length, and velocity, and all that grows out of it. Consequently the more experimenting the pupil can do along these particular lines, and especially the more claborately any experiment he does perform can be interpreted by him, the more definite and important will be what he may gec out of the sabject. Sound is a part of physies frequently more or less reglected, especially in an experimental way, except in so far as it is taught as a collection of curious and interesting phenomena. As a matter of fact, given Melde's experiment, Kundt's experiment, experiments on the vibrations of coiled springs, the tuning fork chronograph, and experiments in resonance, not to mention graphic constructions for simple and complex wave forms and for 